\title{
The New World System and Worldview?
}

\author{
JONATHAN MARSHALL \\ UNIVERSITY OF TECHNOLOGY, SYDNEY
}

\author{
Richard E. Lee \\ Knowledge Matters: The Structures of Knowledge and the Crisis of the \\ Modern World System \\ University of Queensland Press, Brisbane, 2010 \\ ISBN 9780702238420 \\ RRP $\$ 35.00$
}

I approached this book with eagerness and expectation. It is 'the cumulation and distillation of 20 years of work' (8) by a noted associate of Immanuel Wallerstein. The book aims to show that 'World Systems Theory' offers a better explanation for the 'secular crisis of the processes reproducing the interlocking and co-determining material and cultural structures of social life in the modern world', than does information society theory or, presumably, any other alternative. (2) Richard E. Lee's aims are interesting, worthwhile and should command attention.

However, I found this a frustrating and often vague book. Of course, there is the difficulty of covering all relevant factors in a mere 170 pages, but often the gaps are so great that the author's accounts of the historical dynamics read like just-so stories. More detail might have made the points more persuasively. Most of the world system and cultural history considered is British, but it is surely not enough to 
discuss the origins of 'culture' as a crucial term of analysis (86ff.) without mentioning anthropology, or the fraught relations between anthropology and cultural studies. Should analysis of the origins of social systems theory totally ignore Bateson and the Macy conferences? Is it really possible to claim that the Newtonian worldview collapsed because of 'social studies of science', (98) completely ignoring the scientists (however you define them) who produced relativity theory, quantum mechanics, and chaos and complexity theory, either previous to, or without knowledge of, those social studies? Similarly the idea of objectivity was never completely without challenge, although in this book the challenge does not arise until the 1960s. (83) Hume and Berkley demonstrated some problems with objectivity and empiricism, and, if you dismiss them as minor philosophers, we still have Kant and Hegel and a large number of British Hegelians in the nineteenth century. Similarly, Blake, Coleridge, Cardinal Newman and so on, were all uncertain about empirical objectivity. The idea of objectivity has been contested for about as long as it has existed.

When Lee outlines the development of the structures of knowledge (which he claims is a concept originating in World System Theory (22)), the account is again fraught with absences. A simplified past succeeds in making the present look complex, or making the past and its knowledge look stable and structured, thus reinforcing the idea that the present is a transitional period. But every era is, in some sense, a transitional period and most knowledge a form of disputed ignorance. Neatness perhaps results from a general desire for holism, orderliness and completism in most systems theory and I'm not sure that Lee's version entirely escapes this. Perhaps we need to consider the interesting paradox that the term 'holism' was invented by the racial segregationalist, South African General Jan Smuts?

In his history of the melding of imperialism, sexism, racism and idealised culture in the nineteenth century, (67ff.) there are strange elisions, or harmonisations. For example, Carlyle's racism is taken at face value, while his anticapitalism is dismissed. We are given a political history that does not mention Marx or Kropotkin, or widespread activism (just the odd riot). He ignores the factory inspectors, reformist Christians, the patterns of shifting alliances whereby Tories tried to inhibit the power of free traders, and the contribution of popular thinkers 
like Ruskin. Economist J.A. Hobson considered Ruskin's influence on the British Left to be, despite his conservatism, greater than that of Marx. Perhaps Ruskin is not as neatly categorisable as Mathew Arnold might be, and makes less of a smooth pattern in the 'structure' of knowledge? Similarly Herbert Spencer and his followers, whatever their obvious deficiencies, may not have accepted the supposed neat and tight division between values and science. What if cultural dynamics inheres in people escaping neat kinds of categories, in roughness and disorder, in the byways of chaos, as much as in order and structure?

Questionings aside, what is the message of the book? Lee proposes that with the decline of traditional social science, the 'fundamental question' has turned on 'the specification of the basic unit of study of long-term, large-scale social change', and his answer to that question is based on the appearance of Wallerstein's World Systems Theory. (3) It is, however, not clear to me precisely what this basic unit (not units?) is taken to be, although chapter one makes clear it is not the state, tribe or colony. $(10,15)$ The analysis focuses on the 'axial' division of labour, the geopolitical arena, the interstate system and the structures of knowledge, with a brief detour into 'commodity chains' and 'households'. I suspect that, for Lee, the 'basic unit' is not the 'units' themselves, but the relationships between them. (25) Some of these important relationships may appear to be outside the 'unit' being analysed; thus important events could be extraneous to the Mediterranean feudal system but internal to the Mediterranean economy as a whole. Similarly, peasants in Latin America and the proletariat in the UK, although apparently in unrelated systems, are connected by the world system. (18) These necessary events, cycles and connections can also produce conflicts as well as integrations, as when there is little left in the way of potential wage labour outside the system which can be brought in and exploited, leading to a decline in profit rates. (22-3)

Lee points out that there may be recurrent cycles but long-term regularities are 'always changing, never the same from one moment to another'. Eventually, as in Marxism, the contradictions cannot be contained and the system crashes. (20) Despite this, I wonder how much Lee's emphasis on the 'reproduction' of 'structures' leads him to neglect exploration of the equally important dissolution and disordering processes, which may appear as incidental or contingent factors, until collapse occurs. Can we for instance know that the US has lost world 'leadership' 
(38) by anything other than the dissolutive processes in the failure to assert that leadership or have it recognised? On the other hand, the chapter concludes with an interesting discussion of the way metaphors about terrorism frame both the debate and our understanding of what is happening, and thus disorder our responses.

The second chapter explores the dividing of truth from values in the nineteenth century and earlier and later, and the birth of C.P. Snow's 'two cultures'. This apparently corresponds to capitalist trends for commodification and proletarianisation, just as feudal sovereignty 'correlated inversely with the revival and reinvigoration of the principle of the excluded middle' (5) - I presume this latter point is demonstrated elsewhere. The rupture between the two cultures is said to have a series of fluctuations like the long waves in the economic arena. Culture has 'slow initial growth, then builds rapidly and finally flattens out as it approaches an asymptote or limit'. (52) I'm not sure a mathematical limit is quite the same as the 'limits' in culture, but the point is asserted rather than demonstrated and so it is hard to be sure. Another assertion is that the social sciences originated in the processes of attempting to engineer controlled social change, and thus have failed.

The third chapter has an interesting set of references to chaos in the social sciences, (100ff) although again it is not clear whether Lee sees chaos theory as simply another way of looking for hidden order, or as the possibility of something new. He does propose that nowadays the physical world looks more like the social world, (106) suggesting a convergence of practice, but this could also count as a metaphoric reduction of one side or both. He recognises that complex systems are unpredictable, (101) but seems to see this as a matter of limits on variation, so change is still smooth, rather than opening the possibility of normal discontinuity and catastrophic change. Nevertheless this quick summary is one of the best parts of the book.

But chaos theory or multiplicity is not inherently radical or questioning, as Lee appears to assume. It can be used to support the established order as when classic conservatism argues that we do not know the hidden purpose of apparently irrational, messy or oppressive social formations, so we had better keep them. Similarly capitalism can use the idea of the chaos of markets to justify its demands for flexible and adaptable workers, low corporate taxes, and a lack of restraints on working conditions. This issue gains significance when we move, as Lee does, into 
the 'culture wars' (110ff.) and the attack on 'science'. Contrary to Lee, the effective epistemological undermining of science has possibly come more from the 'right' than the 'left' (if we can make such categorisations). Science has declined in influence and respect to the extent scientists have clashed with corporations over health and ecology, and supporters of pro-establishment religions have taken advantage of this struggle to reassert their entitlements to pronounce truth. These critics of science have co-opted the tools developed by supposedly radical cultural and social studies of science, and used them to depict science which is contrary to them as interested, politically biased and epistemologically faulty. This is not a minor issue, but has impacts on the effectiveness of 'leftist' or 'new social movement' approaches to the war over culture, power and the future shape of society. Such 'postmodern' approaches, when taken by radicals, may undermine their own legitimacy, no matter how 'true' they are. This may be a fundamental paradox of modern life and needs exploration. Oddly, in Lee's discussion of these 'wars', there is no consideration of 'new' or 'old' media, and their relationship to the propagation of knowledge and ignorance. This is unexpected in a book that aims to supersede information society theory.

Finally, we are told that World Systems Theory is being built now and will solve all our problems. On the evidence of this book I'm not so sure. The issues are important, the ideas are important, but somehow it doesn't work. Despite the criticisms made here, I will be hoping for another more expansive book from Lee and looking out for his articles. Perhaps, producing a summary of so much work has stressed the expansive and, yes, generous, nature of Lee's thought and has led to too much elision. Perhaps, then, in our 'information age' it is the publisher who is at fault for insisting on untoward compression, and this incompletion is also part of the dynamics of our contemporary 'structures of knowledge'?

Jonathan Marshall is an ARC Research Fellow at the University of Technology, Sydney, researching disorder in computer software and world systems. His books as author include Living on Cybermind: Categories, Communication and Control and as editor Depth Psychology, Disorder and Climate Change. 